\title{
M\&S Highlight: Bischoff and Perry (1991), Compressive behaviour of concrete at high strain rates
}

\author{
John L. Provis $(\mathbb{D}$
}

Received: 20 October 2021/Accepted: 18 December 2021/Published online: 23 February 2022

(C) The Author(s) 2022

The 1991 article by Bischoff and Perry, "Compressive behaviour of concrete at high strain rates" [1], is currently the most-cited article ever published in Materials and Structures, with over 1000 citations according to the Scopus database. This article is a very substantial piece at 26 pages in length, and presents a highly detailed literature review and data compilation that summarises the then-current state of the art related to concrete subjected to compressive load as a function of strain rate. The discussion is derived from the 1988 $\mathrm{PhD}$ thesis of the first author [2], with the additional inclusion of information from 1988 CEB recommendations. The behaviour of concrete under variable strain rates has been a topic of importance and interest since the groundbreaking publication of Abrams in 1917 [3], and this review has offered an invaluable resource to the community by providing both detailed discussion and graphical summaries of the relevant

This commentary is part of our celebration of 75 years of RILEM, highlighting Materials and Structures' most highly influential and cited publications.

Highlighted paper: P.H. Bischoff \& S.H. Perry (1991). Compressive behaviour of concrete at high strain rates. Materials and Structures 24(6), pp. 425-450.

\section{J. L. Provis $(\bowtie)$}

Department of Materials Science and Engineering, University of Sheffield, Sheffield S1 3JD, UK

e-mail: j.provis@ sheffield.ac.uk historical data sets spanning from 1917 until the mid1980s, which had originally been published in languages including English, German, Japanese, and Swedish. The review covers strain rates from $10^{-8}$ to $10^{3} \mathrm{~s}^{-1}$-i.e., from creep to blast loading (Fig. 1).

The main focus of the review and discussion of Bischoff and Perry [1] is on the higher strain rate range, considering the types of strain rates induced by impacts and blasts. This is an important and challenging range in which to conduct experimental testing, and the review provides key insights and recommendations regarding how such high strain rates can be applied and controlled accurately, and how factors such as inertial effects within the specimen and apparatus can be appropriately incorporated into analysis of the results obtained. There have been obvious advances since the date of publication because of the digitalisation of experimental setups, which has offered a step-change in the ability to control, measure and interpret processes which take place as rapidly as the experiments discussed here, but the wisdom embodied in the recommendations provided by Bischoff and Perry is highlighted by the fact that their paper continues to be used and highly cited 30 years after publication.

The latter sections of the paper of Bischoff and Perry [1] provided discussion of the relationships embodied in the compiled data sets for compressive strength and for deformation behaviour, and analysed 


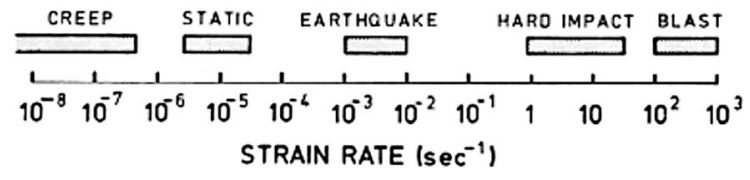

Fig. 1 Magnitudes of strain rates that can be imposed on concretes in compression, classified by Bischoff and Perry [1] according to loading cases which can induce each strain rate. Copyright 1991 RILEM Publications

the physical meanings underpinning some of these. A logarithmic relationship between strain rate and measured uniaxial compressive strength was proposed, with the material returning a higher measured strength (or higher Dynamic Increase Factor, DIF, which is defined as the ratio of measured strength at a given strain rate to the static strength) as the strain rate is increased above levels corresponding to static testing $\left(\sim 10^{-5} \mathrm{~s}^{-1}\right)$. There is a very wide scatter in the collected data, Fig. 2, and the 1988 CEB recommendations show a prediction of bilinear behaviour with a change in gradient at a strain rate of $30 \mathrm{~s}^{-1}$. These recommendations contain a concrete grade (compressive strength) dependence which has been updated in later formulations such as the fib Model Code 2010.
There is significant difference between various equations that have been proposed, and encoded in standards, to describe the strain rate dependence of compressive strength [4], and the uncertainty and causes of experimental scatter identified by Bischoff and Perry have evidently propagated into the different expressions utilised by different standardisation bodies. This includes discussion at a fundamental level regarding whether the observed high-strain-rate increase in DIF is actually a material property at all, or whether this behaviour is in large part (or even solely) due to lateral confinement from inertial and frictional effects during testing [5, 6]. Bischoff and Perry [1] discussed this as a possible interpretation of the available data, but as a possibility rather than as a confirmed conclusion, and subsequent investigations have further explored this possible interpretation from both experimental and numerical modelling viewpoints as the range of available techniques has advanced over the past 30 years.

The Bischoff and Perry data set is still used as a reference point to provide graphical comparisons of different strain rate dependency relationships and reproduced in other published papers, e.g. [5, 8],

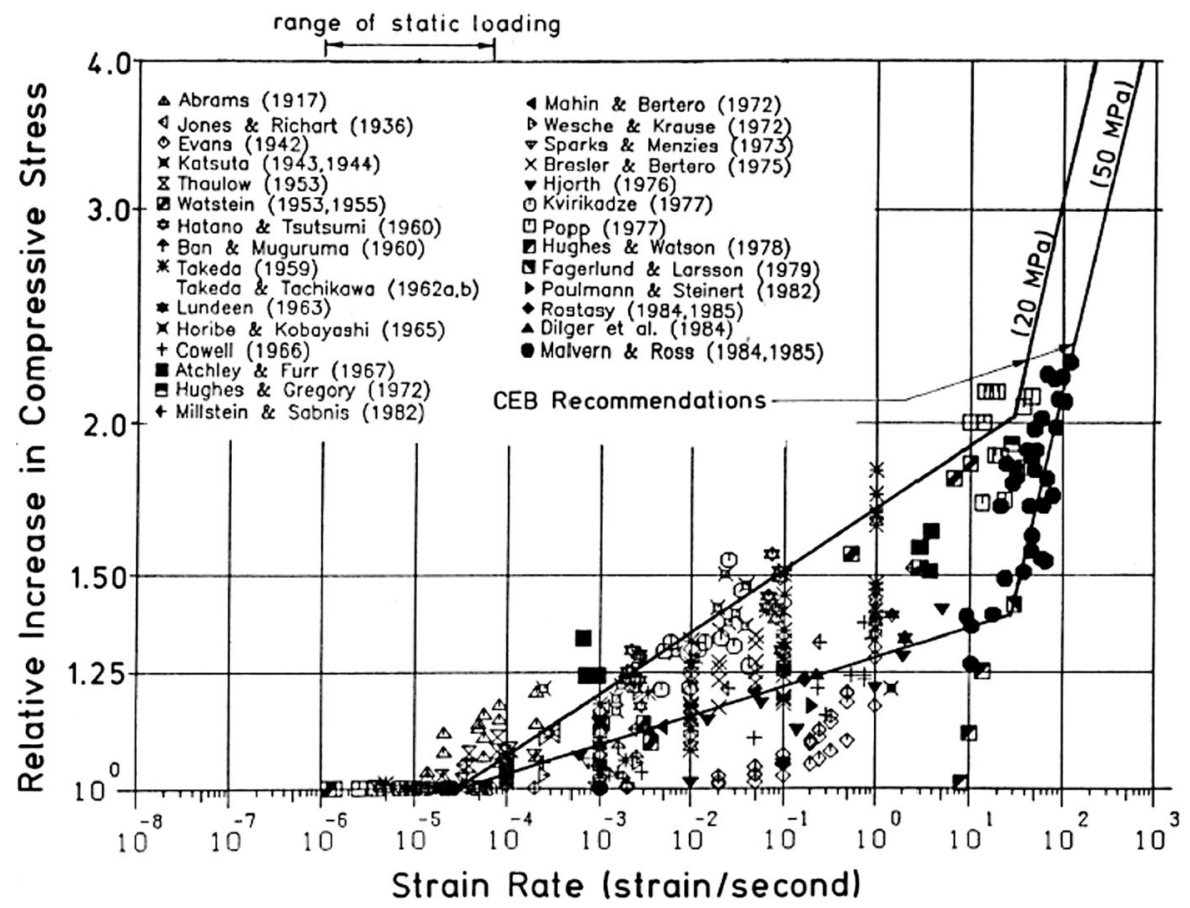

Fig. 2 Influence of strain rate on compressive strength of concretes, along with the 1988 CEB recommendations [7]. Reproduced from [1], Copyright 1991 RILEM Publications

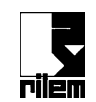


showing the enduring value of this work as a collection and critical assessment of a very large body of data. Their analysis has also been used as a key reference point in studies of materials other than concrete, particularly in the field of rock mechanics [9], and also for analogous studies of concrete under applied tensile force at high strain rates [10]. The influence of moisture on the strain rate dependence of mechanical properties was mentioned only briefly by Bischoff $\&$ Perry [1], but subsequent work-including the text of the 1996 RILEM Robert L'Hermite Medal lecture of P. Rossi [11] — has added significant depth to the available technical insight in this area.

Current RILEM work related to this topic includes TC 288-IEC "Impact and Explosion" (https://www. rilem.net/groupe/288-iec-impact-and-explosion-377) which has produced outputs including a database of high strain-rate test facilities [12] and is closely connected to an Action Group of fib (TG10.1 AG12, Impact and Explosion). The intention of this group is to ensure that documents such as the fib Model Code can enable structural designers to more fully reflect the state of the art in materials testing and development. Such initiatives clearly depend on the availability of high-quality, critically-assessed databases, and this is one of the key contributions which has led the 1991 paper of Bischoff and Perry [1] to be such a prominent and highly-cited contribution to the technical literature, and the most-cited Materials and Structures article published to date.

Acknowledgements Thanks are due to Professor Peter Bischoff for helpful discussions, and for providing the bestavailable versions of the graphics from the original paper for reproduction here.

Open Access This article is licensed under a Creative Commons Attribution 4.0 International License, which permits use, sharing, adaptation, distribution and reproduction in any medium or format, as long as you give appropriate credit to the original author(s) and the source, provide a link to the Creative Commons licence, and indicate if changes were made. The images or other third party material in this article are included in the article's Creative Commons licence, unless indicated otherwise in a credit line to the material. If material is not included in the article's Creative Commons licence and your intended use is not permitted by statutory regulation or exceeds the permitted use, you will need to obtain permission directly from the copyright holder. To view a copy of this licence, visit http://creativecommons.org/licenses/by/4.0/.

\section{References}

1. Bischoff PH, Perry SH (1991) Compressive behaviour of concrete at high strain rates. Mater Struct 24(6):425-450

2. Bischoff PH (1988) Compressive response of concrete to hard impact. Ph.D. thesis, Department of Civil Engineering. Imperial College of Science and Technology. $295 \mathrm{pp}$

3. Abrams DA (1917) Effect of rate of application of load on the compressive strength of concrete. ASTM Proc 17:366-377

4. Lee S, Kim K-M, Park J, Cho J-Y (2018) Pure rate effect on the concrete compressive strength in the split Hopkinson pressure bar test. Int J Impact Eng 113:191-202

5. Mu ZC, Dancygier AN, Zhang W, Yankelevsky DZ (2012) Revisiting the dynamic compressive behavior of concretelike materials. Int J Impact Eng 49:91-102

6. Zhang M, Wu HJ, Li QM, Huang FL (2009) Further investigation on the dynamic compressive strength enhancement of concrete-like materials based on split Hopkinson pressure bar tests. Part I: Experiments. Int J Impact Eng 36(12):1327-1334

7. Comité Euro-International du Béton (1988) Concrete structures under impact and impulsive loading. Synthesis report, bulletin d'information No. 187. Lausanne

8. Borosnyói A (2014) Compressive strength of normal and high strength concretes under combined influence of loading rate and service temperature. Period Polytech Civ Eng 58(4):347-353

9. Zhang QB, Zhao J (2014) A review of dynamic experimental techniques and mechanical behaviour of rock materials. Rock Mech Rock Eng 47(4):1411-1478

10. Malvar LJ, Ross CA (1998) Review of strain rate effects for concrete in tension. ACI Mater J 95:735-739

11. Rossi P (1997) Strain rate effects in concrete structures: the LCPC experience. Mater Struct 30(1):54-62

12. RILEM TC 288-IEC (2020) Experimental devices harvest for impact and explosion testing of materials and structures. $31 \mathrm{pp}$

Publisher's Note Springer Nature remains neutral with regard to jurisdictional claims in published maps and institutional affiliations. 